\title{
Potential energy savings achievable by zoned control of individual rooms in UK housing compared to standard central heating controls.
}

\section{J. Cockroft*, A. Cowie, A. Samuel, P. Strachan}

jeremy.cockroft@strath.ac.uk, andrew.cowie@strath.ac.uk, aizaz.a.samuel@strath.ac.uk, paul.strachan@strath.ac.uk

Energy Systems Research Unit, University of Strathclyde, 75 Montrose Street, Glasgow, G1 1XJ, Scotland, UK

*corresponding author

\section{Abstract}

1 Energy is wasted in domestic buildings when rooms that are heated are not occupied.

2 Allowing those rooms to cool reduces the inside - outside temperature difference and

3 therefore rate of heat loss, resulting in an energy saving. This suggests a cost effective

4 way to upgrade an existing modern heating system, especially in older properties where

5 other energy saving possibilities are limited. Assessing the savings achievable requires

6 an analysis of a range of influencing factors, such as house type and age, location and

7 occupancy patterns. Door opening has a major influence due to the impact on air

8 exchange between heated and unheated zones in a house, so this was also considered.

9 Annual simulations were carried out on dynamic models of the thermal and air flow

10 interactions, for all combinations of influencing factors, to compare the potential energy

11 savings of zoned versus non-zoned control.

12 Savings of between $12 \%$ and $31 \%$ were obtained in the case of a semi-detached house

13 model, and between $8 \%$ and $37 \%$ for a single storey bungalow. The largest percentage

14 savings occurred in older properties, with interconnecting doors kept closed, and for the

15 more intermittent types of occupancy. The average saving obtained for both house

16 types was around $20 \%$.

\section{Keywords}

17 Multi-zone zone zoning control modelling simulation occupancy heating saving energy 


\section{Introduction}

18 Reducing energy consumption in homes, largely driven by the need to meet carbon

19 dioxide emission reduction targets, is being achieved in new build properties

20 predominantly through higher insulation standards, increased air tightness and more

21 efficient domestic lighting and appliances. However, at least $80 \%$ of the building stock

22 that will exist in 2050 is already built (Royal Academy of Engineering 2010), so

23 increasing attention is being paid to finding energy saving solutions for existing

24 properties. Relatively simple and cost effective measures such as loft insulation, cavity

25 wall insulation, weather stripping, and boiler replacement are widely deployed. More

26 costly and invasive demand reduction measures include replacement windows, and

27 internal or external wall insulation. Further measures usually involve the deployment of

28 renewable technologies, such as solar thermal and PV panels, biomass boilers and heat

29 pumps. These solutions are heavily promoted by manufacturers, but are expensive, and

30 significant uptake is driven by government aid programmes such as the Renewable Heat

31 Incentive and the Energy Company Obligation (OFGEM 2016).

32 Heating controls are a neglected technology in the home, and although there is now

33 acceptance that time and temperature control can reduce energy use, mainly by

34 avoiding unnecessary fuel use, there is a lack of knowledge or understanding as to what

35 technologies and techniques could be applied to obtain the maximum benefit in

36 particular instances. Only in recent years have even the simplest domestic heating

37 controls become a standard for new heating systems in the UK, the minimum installation

38 requiring a single time and temperature control zone for floor areas up to $150 \mathrm{~m}^{2}$, and

39 two independent time and temperature control zones for floor areas greater than $150 \mathrm{~m}^{2}$.

40 Thermostatic radiator valves (TRVs) are required on all radiators except in the room

41 where the thermostats are located (HM Government 2013). Even this basic standard

42 level of control does not exist in $70 \%$ of UK homes (Consumer Focus, 2012). More 
43 advanced thermostats, usually combining time and temperature programming, allow

44 more complex profiles to be accommodated, and this can lead to some additional

45 savings. Until recently, this level of control sophistication was all that could be achieved

46 by automatic control, using standard components available to installers. Recent

47 developments now offer a practical means of controlling the environment in individual

48 rooms in a house.

49 These technologies allow the thermostatic radiator valve head (the part that actuates the

50 valve) to be replaced by a wirelessly controlled motorised actuator. By this means,

51 every room can be controlled independently, so heating can be turned off in those rooms

52 not in use during parts of the day, or temperatures may be increased in a room without

53 affecting the heat supply to the rest of the property. A central control unit receives the

54 demands from all radiators, and switches the boiler on or off as required to meet the

55 current demand throughout the day. This is a relatively low cost retrofit option in many

56 existing homes, no alterations to pipework and only minimal additional wiring being

57 required. By this means, energy savings should be achievable, compared to single point

58 time and temperature control of the entire heating system.

59 There remains a substantial proportion of the housing stock for which the more

60 conventional solutions are difficult to apply, due to architectural, location and

61 conservation constraints. In contrast, multi-zone heating system controls suffer no such

62 constraints, and can often be installed as an upgrade to an existing heating system.

63 The premise under investigation is that a multi-zone control system could offer a means

64 to save energy in many existing properties, as an alternative, or addition to the

65 conventional solutions. The purpose of this paper is to demonstrate a range of potential

66 energy savings achievable by deployment of multi-zone controls for a variety of

67 occupancy patterns in various UK house types, locations, and ages. This will indicate

68 what overall energy saving could be achieved by deploying multi-zone controls in 
69 existing housing on a national basis, and lend additional weight to the argument that

70 such systems should receive more recognition and support by government agencies

71 responsible for determining the scope of standard assessment procedures and incentive

72 schemes.

73 The approach of this study was to use dynamic computer modelling and simulation,

74 using the open source building performance simulation (BPS) package ESP-r (Clarke,

75 2001), which has been developed over three decades by the Energy Systems Research

76 Unit (ESRU) at the University of Strathclyde and a global community of users. ESP-r is

77 used to carry out all aspects of building performance appraisal within a modelling

78 environment that accounts for thermal energy flows, air flows and climate interactions.

79 To ensure that the simulation results were credible, a validation check was carried out

80 using published data from a monitored site.

\section{Multi-zone control behaviour}

81 Multi-zone control in a domestic property achieves energy savings, compared with single

82 zone control, because radiators in rooms that would otherwise be heated can be turned

83 off or adjusted to reduce heat output. The achievable energy saving will depend on the

84 extent to which the temperatures in such rooms fall before heating is again required in

85 those rooms. This in turn is dependent on room location, duration of the off (or reduced

86 temperature setpoint) period, thermal exchange with connected rooms or zones, the

87 overall insulation level of the property, internal gains, solar gains and the external

88 temperature. For example, a room in a semi-detached property with other heated rooms

89 on all sides and below, will not cool down as rapidly as a corner room in a bungalow,

90 and therefore will deliver a lower energy saving if turned off for short periods. Turning

91 the heating off in a room for a longer period will increase the obtainable energy saving

92 per unit time, because a lower average temperature, and therefore lower heat loss to the

93 external environment, will be experienced. A room with an open door into a 
94 neighbouring zone will gain heat from that zone as long as the temperature is lower, and

95 this will reduce the energy saving in that room, and increase the energy required to

96 maintain temperature in the connected zone. The potential for energy saving will also be

97 affected by the overall external fabric insulation levels. A well-insulated building will not

98 lose heat very rapidly from a room with no heating, so the potential energy savings will

99 be quite low compared with an older, unimproved property. A similar property in a cooler

100 climatic location would also be expected to achieve greater energy savings (though not

101 necessarily in proportion to its total energy consumption).

102 The study therefore included variations in parameters that would allow observation of

103 these various effects on the savings due to multi-zone control.

\section{Previous Studies}

104 Given the energy saving potential of multi-zone control, it has received surprisingly little

105 attention in the published literature. On the other hand, there are several papers that

106 demonstrate the benefit of simple controls (such as a single thermostat with timed

107 control and TRVs) over poorly controlled systems (e.g. timed boiler on/off control).

108 However, empirical studies are difficult to undertake at a scale that may lead to reliable

109 estimates of savings, and both measurement and modelling studies that have been

110 undertaken show a large range in potential savings. For example, Peffer et al (2011)

111 undertook a review of thermostat studies in North America and found reported energy

112 savings from the use of programmable thermostats varying from zero to $9 \%$. Liao et al

113 (2005) reviewed current practice regarding control of heating systems in residential

114 buildings in the UK and Peeters et al (2008) undertook a similar study in Belgium. In

115 both cases, they demonstrated the inefficiency of many installations, and concluded that

116 overall efficiency is affected markedly by the boiler size, the choice of boiler control,

117 whether weather compensation is applied, and the particular configuration of a control

118 thermostat and TRVs. 
119 Regarding multi-zone control, a detailed experiment was undertaken by Beizaee et al

120 (2015) on a matched pair of semi-detached houses: in one house the space heating was

121 controlled with a single thermostat with timed control and TRVs; in the other, zonal

122 control was used to heat rooms only when they were occupied. More details of the

123 experiment are given in the Model Validation section in this paper where the published

124 data are used as a check on the modelling work. Extrapolating the results to the range

125 of UK climates, it was concluded that zonal control could reduce space heating by

126 around $12 \%$ for the un-refurbished 1930's houses that were tested.

127 Meyers et al (2010) undertook a high level scoping study of the potential energy savings

128 in US residential buildings resulting from better control and increased appliance

129 efficiency. Technologies they considered were programmable thermostats, smart meters

130 and outlets, zone heating, automated sensors, and wireless communication

131 infrastructures. They estimated that in the order of $4.2 \%$ of primary energy is wasted by

132 heating and cooling unoccupied houses, $6.2 \%$ is wasted by heating or cooling living

133 areas during the daytime, and $9.7 \%$ is wasted heating and cooling bedrooms when the

134 house is occupied, but the bedrooms are not being used.

135 Leow et al (2013) undertook a modelling study on occupancy-moderated zonal

136 temperature control. They developed algorithms that would control different house

137 zones based on occupancy, including demand-response adjustments to heating and

138 cooling based on the prevailing electricity price. They showed, for zoning control (without

139 demand-response load shifting) over a range of climates in the USA, overall savings

140 averaging around $23 \%$, depending on the particular configuration. Potential cooling

141 energy savings were found to be higher than heating energy savings. The reference for

142 the calculated savings was the whole house heated or cooled to the chosen set-point

143 temperatures of $23.9^{\circ} \mathrm{C}$ for cooling and $21.1^{\circ} \mathrm{C}$ for heating. 
144 An interesting study on the attitudes of residents to controls was undertaken by Rubens

145 and Knowles (2013). The literature on controls show that potential energy savings are

146 often not achieved due to user factors, particularly the difficulty of understanding

147 controls. However, from an in-depth survey and interviews with 43 householders, they

148 concluded that participants seemed to want more rather than less active involvement in

149 their heating, with a greater degree of control. The participants also wanted to be able to

150 see how their behaviours related to their spending on heating. The authors' analysis

151 suggested that remote and zonal control could be combined, with automation as an

152 optional layer so that users could try it out and build trust in it over time.

\section{Model Construction}

153 Two geometrical construction types were included in the study; a typical UK semi-

154 detached property on two floors, and a typical single floor detached bungalow property.

155 This would show up the effect of different zone interactions due to these main

156 construction types.

157 Four different occupancy patterns were simulated, corresponding to:

Young four person family with two children Four person family with two teenagers Elderly couple Young couple
(YF)

(YC)

162 As the authors could not locate any standard heating profiles to represent multi-zone

163 occupancy, these patterns were constructed to represent a range of typical occupancy

164 profiles with different levels of occupancy intensity and variations in timing. For each

165 occupancy pattern, the number of occupants in each zone and the internal heat gains

166 were assigned on an hourly basis according to each profile. These occupancy profiles

167 are shown in Appendix A.

168 Simulations were carried out for each house with standard heating controls (temperature

169 controlled in each room but only one time programme for the whole house), and with a 
170 zoned heating control system with independent time and temperature control in each

171 room. These were called the non-zoned and zoned control strategies respectively. In

172 each case, heat was delivered via radiators in each room with a 50/50 radiant/convective

173 split. Radiators were sized at $1.75 \mathrm{~kW}$ per zone for the semi-detached house, and $2 \mathrm{~kW}$

174 per zone in the bungalow, to ensure a rapid heat up (maximum 30 minutes) to the set

175 point temperatures, which were then maintained by an idealised control, without on/off

176 fluctuations or load influenced deviations from set point. Thermostats in both zoned and

177 non-zoned cases sensed a 50/50 mix of air and mean radiant temperatures. Details of

178 the heating schedules are also shown in Appendix A.

179 In order to assess the effect of insulation and air-tightness on energy consumption,

180 construction material thermal properties were adjusted to create models that meet

181 minimum building standards corresponding to four age categories as defined by the UK

182 government Standard Assessment Procedure (SAP) (BRE, 2014). These changes in

183 building standards delineate major changes in the level of insulation and airtightness and

184 are used for comparing the energy and environmental performance of buildings of

185 varying ages in the UK by SAP. The age bands chosen were C, F, I and K (England \&

186 Wales) and the corresponding fabric properties are shown in Table 1.

Table 1 Property age bands and construction properties

\begin{tabular}{|l|l|l|l|l|}
\hline Band & Year range & $\begin{array}{l}\text { Wall U-value } \\
\text { W/m } \mathrm{m}^{2} \mathrm{~K}\end{array}$ & $\begin{array}{l}\text { Roof U-value } \\
\mathrm{W} / \mathrm{m}^{2} \mathrm{~K}\end{array}$ & $\begin{array}{l}\text { Ventilation rate } \\
\text { ac/h }\end{array}$ \\
\hline $\mathrm{C}$ & $1930-49$ & 2.0 & 2.0 & 0.5 \\
\hline $\mathrm{F}$ & $1976-82$ & 1.0 & 1.2 & 0.4 \\
\hline $\mathrm{I}$ & $1996-2002$ & 0.45 & 0.43 & 0.4 \\
\hline $\mathrm{K}$ & 2007 on & 0.3 & 0.3 & 0.3 \\
\hline
\end{tabular}

U-values are approximate.

187 Two UK climatic locations were chosen, corresponding to London (Heathrow), England,

188 and Glasgow (Abbotsinch), Scotland. TRY (test reference year) data for these locations

189 were used to ensure representative boundary conditions. The dry bulb temperature,

190 direct normal radiation, and wind velocity data are summarised in Appendix B. Diffuse 
191 horizontal radiation and wind direction are also contained in the weather files, and used

192 in the simulations.Figure 1 is a view of the model of the semi-detached property, and

193 Figure 2 a view of the bungalow. Rendered views looking from the south-west, and

194 wireframe views in plan are shown, and for clarity representations of internal thermal

195 mass are not shown. 

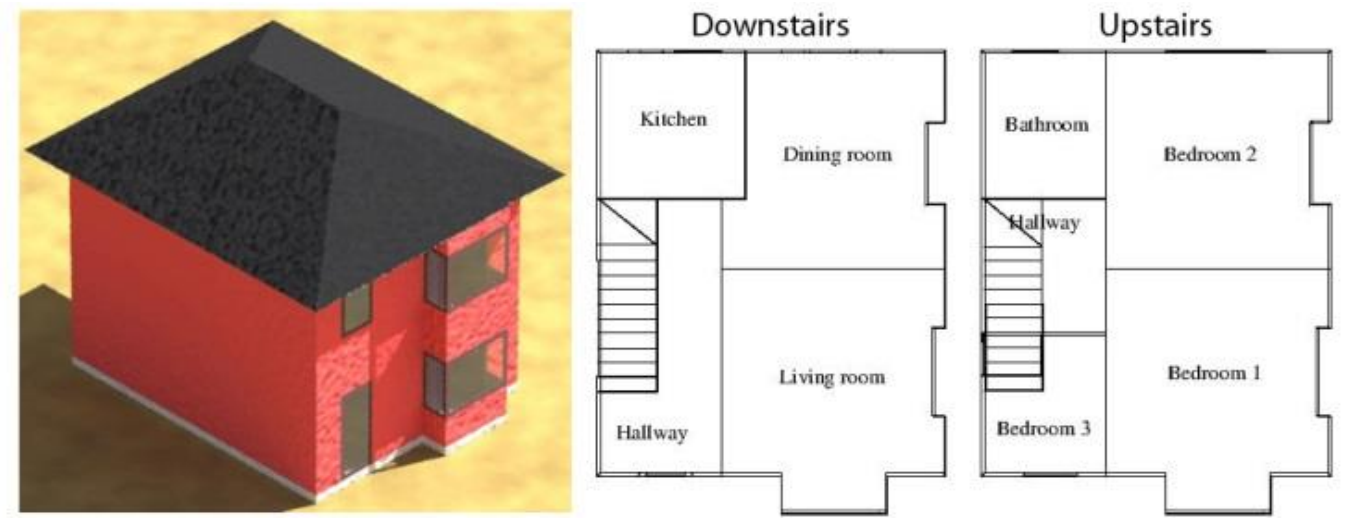

Figure 1 model of semi-detached property
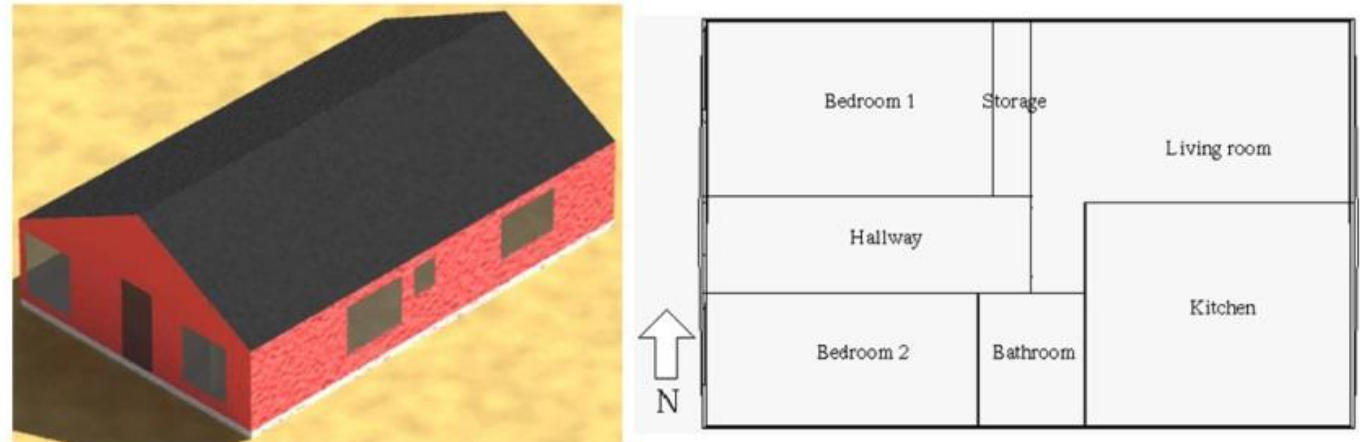

Figure 2 model of bungalow

196 The semi-detached house includes nine separate zones, heated except where indicated:

Z1 Downstairs hallway

Z2 Living room

Z3 Dining room

Z4 Kitchen

Z5 Upstairs hallway
Z6 Bedroom 1

Z7 Bedroom 2

Z8 Bedroom 3

Z9 Bathroom (not heated)

197 The bungalow includes six separate zones, heated except where indicated:

\section{Z1 Bedroom 2}

Z2 Hallway

Z3 Bedroom 1
Z4 Living room

Z5 Bathroom (not heated)

Z6 Kitchen

198 The hall heating schedule follows that of the living room. The temperature in the

199 bathroom is free floating.

200 In all cases, the set point temperature in all rooms during heating periods is $20^{\circ} \mathrm{C}$

201 operative temperature. 

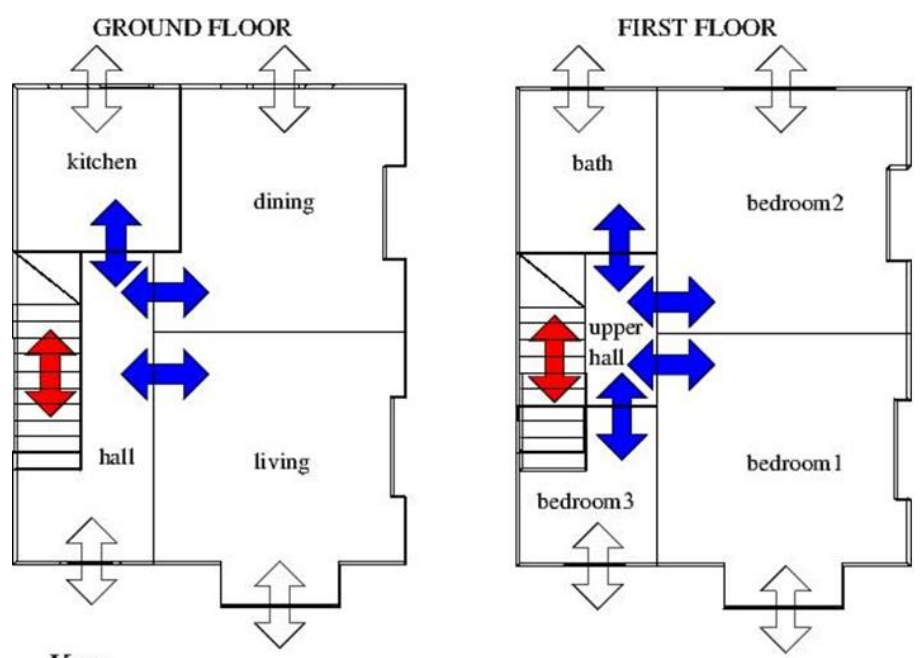

Key

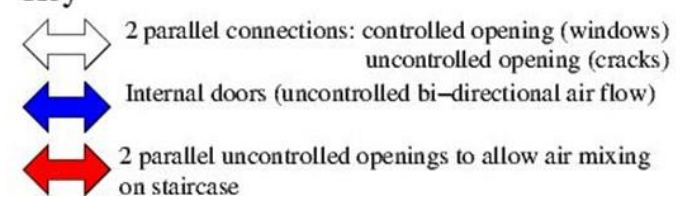

Figure 3 Airflow network for semi-detached house.

202 The effects of wind and buoyancy on air flows and air exchange between zones are

203 important factors affecting energy consumption in a zoned house. The air flow network

204 used in the model of the semi-detached house is illustrated in Figure 3. For clarity,

205 connections between internal zones representing cracks in "solid" constructions are not

206 shown; these connections generally represent insignificant flows compared to the

207 connections detailed in Figure 3. Bi-directional airflows may occur through doorways

208 due to the combined effects of external wind and internal temperature differences.

209 Windows were modelled as operable, and each was subject to a proportional control

210 such that opening area was linearly proportional to dry bulb temperature in the

211 appropriate zone between 25 and $28^{\circ} \mathrm{C}$. Windows were closed at and below $25^{\circ} \mathrm{C}$, and

212 fully open (with area of $2.5 \mathrm{~m}^{2}$ ) at and above $28^{\circ} \mathrm{C}$. This was intended to model typical

213 occupant behaviour in preventing rooms from overheating. A similar flow network was

214 constructed for the bungalow model. In the semi-detached house, air will also flow

215 vertically between the ground and upper levels, mainly driven by buoyancy effects. In

216 order to assess the impact of air flow on the performance of the houses, four levels of 
217 door opening were modelled, corresponding to average door opening areas of $0,10,50$

218 and $100 \%$ of full door open area. This was applied to the full door opening area to each

219 room in each house.

\section{Model Validation}

220 Numerous extensive validation exercises have been carried out on ESP-r over many

221 years, involving analytical, inter-program and empirical evaluations (Strachan et al,

222 2008). To build further confidence in the modelling approach, specifically to build

223 confidence in the results of multi-zone simulations, we identified the work of Beizaee et

224 al. (2015) as being of particular significance. Beizaee et al. carried out simultaneous

225 measurements of energy consumption in a side-by-side comparison of two semi-

226 detached properties, one with conventional single zone heating control, and one with a

227 multi-zone system as described above. This experiment demonstrated the potential for

228 energy saving. The details of these properties have been used to create a dynamic

229 simulation model in ESP-r to verify that the computed energy data predicts the energy

230 savings that were observed by Beizaee et al.

231 The properties were an adjoining pair of semi-detached houses built around the 1930s,

232 typical of UK housing stock of this period. They were located in Loughborough in the

233 East Midlands, England. The properties had not been significantly modified since they

234 were built, and thus had poorly insulated envelopes including single glazed windows, no

235 cavity wall insulation and no loft or floor insulation. Beizaee et al. reported a blower door

236 (pressurisation) test on both properties, finding that both were rather leaky at

237 approximately $21 \mathrm{ac} / \mathrm{h}$ at 50 Pa pressure difference.

238 These properties were very similar to the semi-detached dwelling model that was

239 developed for this study. The validation strategy adopted was to calibrate a variant of

240 the model with the conventional non-zoned control, by adjusting the fabric thermal

241 properties and leakage distribution to achieve reasonable agreement in terms of energy 
242 consumption and temperature statistics. The control parameters were then changed to

243 represent the multi-zone controller. Simulations of the calibrated model were then

244 carried out for the periods for which the houses were monitored, using contemporaneous

245 weather data, and internal gain profiles as described by Beizaee et al. The monitoring

246 periods were $16^{\text {th }} \mathrm{Feb}-15^{\text {th }} \mathrm{Mar}, 18^{\text {th }} \mathrm{Mar}-8^{\text {th }} \mathrm{Apr}$ and $16^{\text {th }} \mathrm{Apr}-21^{\text {st }} \mathrm{Apr} 2014$. The

247 predicted savings resulting from the two control options were compared to the measured

248 savings in the side-by-side experiment. Figure 4 compares the model and the measured

249 differences in average temperatures during the heating periods in each zone, with and

250 without zone control. In all cases the differences are negative, due to the shorter

251 heating periods in each zone with zoned control.

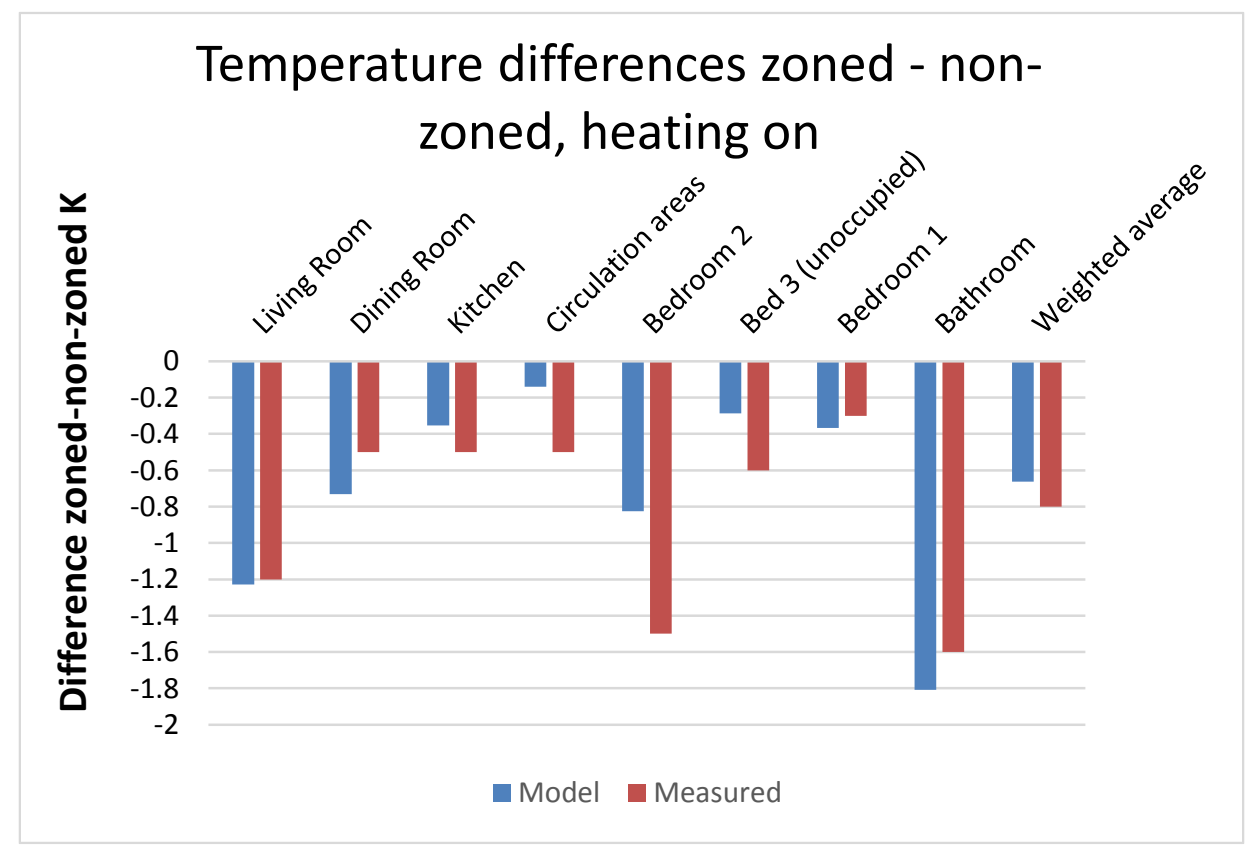

252 Figure 4 Comparison of temperature differences zoned - non-zoned, heating on

254 Table 2 shows the results that were obtained by simulation, compared with the

255 measurements by Beizaee et al. of energy consumed over the reported monitoring

256 period. Good agreement was obtained with the measurements, which increases our

257 confidence in the results for the parametric study. As an initial indicator of annual saving 
258 potential, the ESP-r simulation estimated an average consumption of $62.6 \mathrm{kWh} /$ day with

259 zoning, a saving of $11.8 \%$ when compared with the non-zoning case.

Table 2 Comparison of measured and simulated energy consumptions from validation study

\begin{tabular}{|l|l|l|l|}
\hline & $\begin{array}{l}\text { Energy consumption, not } \\
\text { zoned }\end{array}$ & $\begin{array}{l}\text { Energy consumption, } \\
\text { with zoning }\end{array}$ & $\begin{array}{l}\text { Energy } \\
\text { Saving }\end{array}$ \\
\hline $\begin{array}{l}\text { Beizaee et al. } \\
\text { measurements }\end{array}$ & $62.4 \mathrm{kWh} /$ day (average) & $53.6 \mathrm{kWh} /$ day (average) & $14.1 \%$ \\
\hline ESP-r estimates & $62.6 \mathrm{kWh} /$ day (average) & $55.2 \mathrm{kWh} /$ day (average) & $11.8 \%$ \\
\hline $\begin{array}{l}\text { Estimate as } \% \text { of } \\
\text { measured }\end{array}$ & $100.3 \%$ & $103.0 \%$ & $83.7 \%$ \\
\hline
\end{tabular}

\section{Simulation method}

260 Simulations were carried out for each house type (semi-detached and bungalow), for

261 each of four age bands, for each climate location (Glasgow and London) for each of four

262 occupancy types, and for four door opening percentages (0-100\%). Each simulation

263 was carried out for one year.

264 Thus, a total of 256 annual simulations were run, each with a 24 day pre-simulation start

265 up period in order to eliminate initialisation assumptions, and using 5 minute time steps.

266 The runs were automated using shell scripts in a UNIX environment. 


\section{Simulation Results}

267 Results comparing internal operative temperatures across all simulation runs are

268 presented for a typical one week winter period. Results comparing energy

269 consumptions are presented for the annual result.

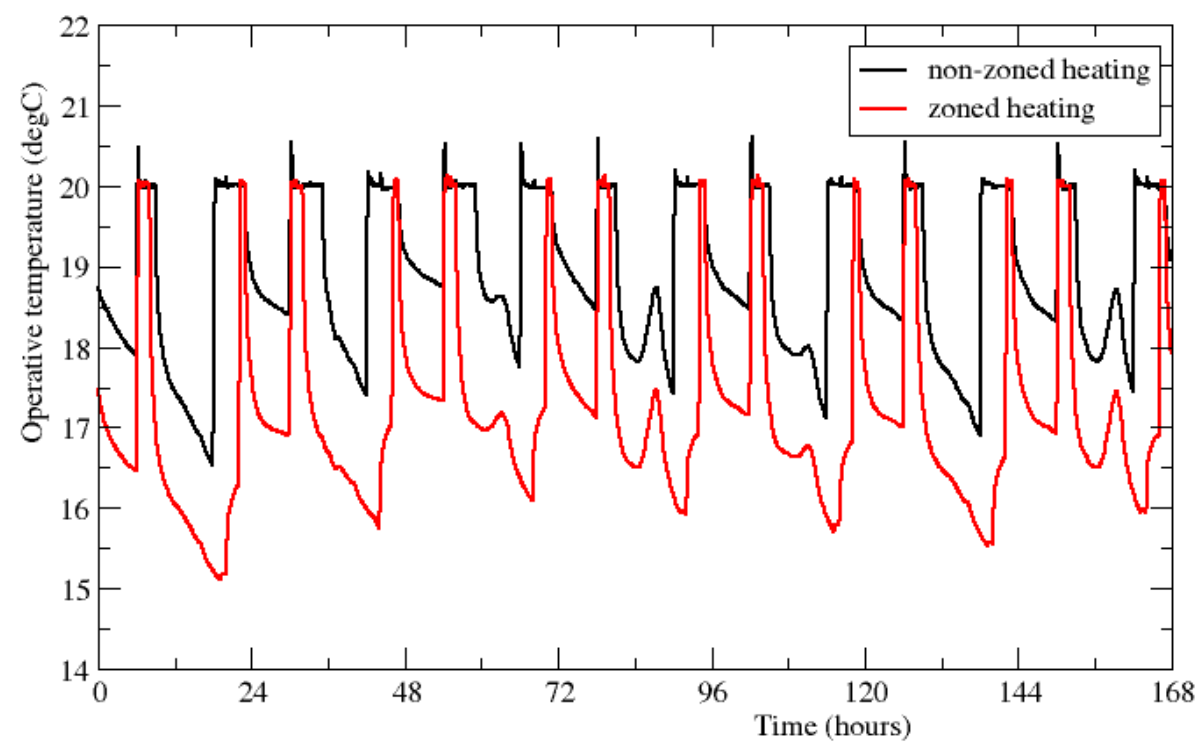

Figure 5 Typical operative temperatures over a winter period in the bungalow

270 Figure 5 shows the operative temperatures in bedroom 1 in the bungalow model, for YC

271 occupancy, age band K, London climate, doors closed, with and without zoning over a

272 seven day winter period. Providing heat only during the much shorter occupied periods

273 (zoned heating) results in lower temperatures during the unoccupied periods and thus an

274 energy saving compared to the non-zoned case.

275 Figure 6 shows the effect of occupancy (YF, FT, EC and YC as described in the Model

276 Construction section) on the average living room temperature during occupied hours in

277 the semi-detached house for the non-zoned case. For each occupancy type, the

278 average temperature is shown as a function of climate (Glasgow or London), and house

279 construction age band. For each case, a range of four values is plotted corresponding to

280 four door opening percentages $(0,10,50$ and $100 \%)$. 


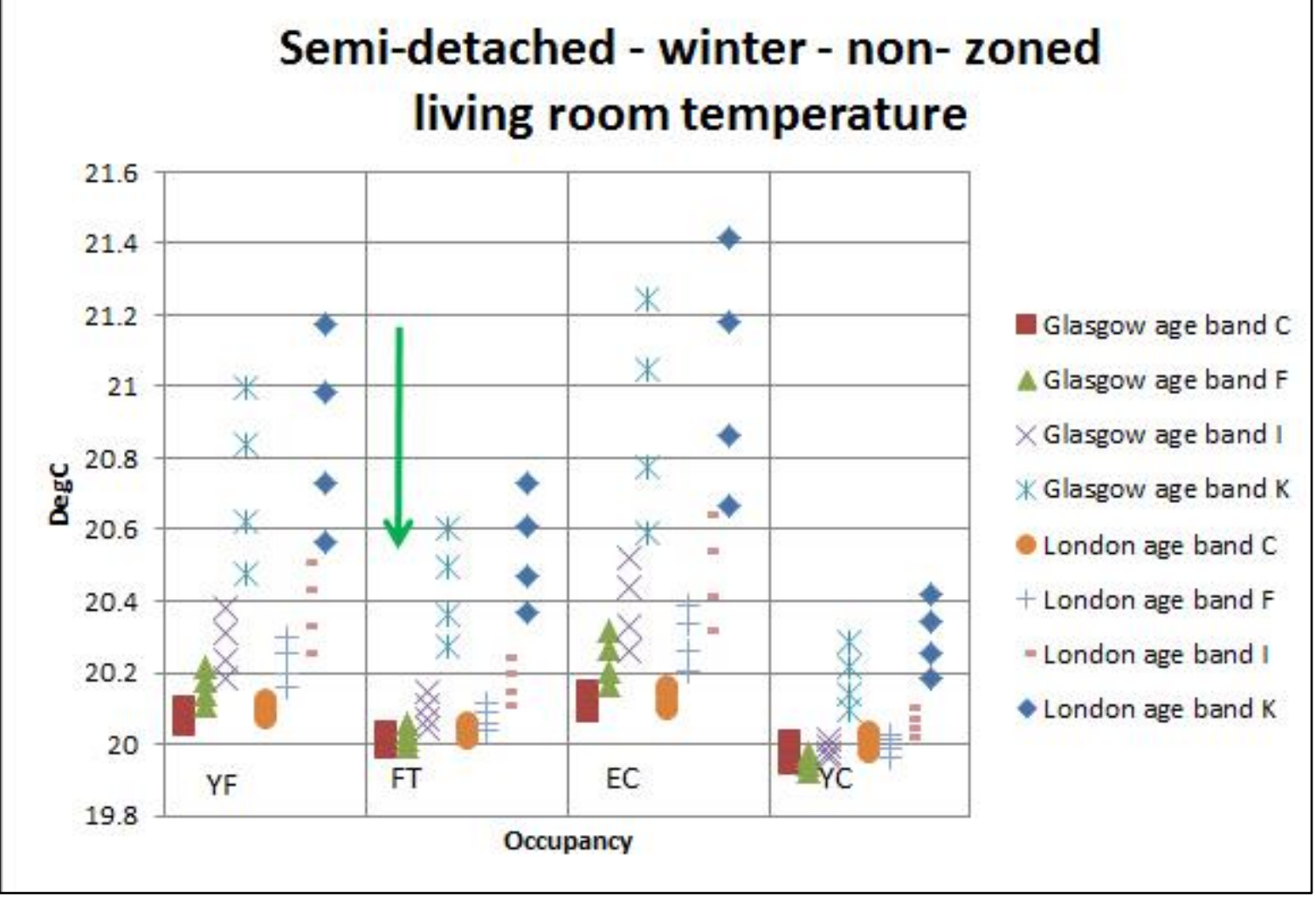

Figure 6 - Effect of occupancy on winter living room temperature (Semi-detached house, winter, non-zoned case)

281 The arrow indicates the direction of increasing door opening area. When doors are fully

282 open, air can pass freely between zones, so heated zones will lose heat to unheated

283 zones. This will tend to increase the heat demand of the heated zones and, because

284 they will take longer to reach their setpoint temperature at the start of each occupied

285 period, will reduce their average temperature over each occupied period. Therefore, the

286 lowest temperatures correspond to the $100 \%$ door open cases, and the highest

287 temperatures to the door closed case. However the range in each case is quite small

288 with a maximum of $0.8 \mathrm{~K}$ for the EC case. Some observations may be made:

289 - The temperatures in the YC (young couple) case are generally slightly lower than in

290 the other occupancy cases, due to lower internal heat gains throughout the day and,

291 to some extent, set point temperatures not being achieved due to shorter heating on

292 periods. 
- There is a tendency toward higher temperatures as insulation standards improve,

294 and for the milder London climate. The highest temperatures are observed in the YF

295 (young family) and EC (elderly couple) cases, in the milder London climate, for the

296 best insulated $\mathrm{K}$ age band houses. This is expected due to the longer heating

297 periods, and therefore shorter heating start up times. The effect of door opening

298 percentage is greatest in these cases, due to the larger impact of inter-zone heat

299 transfer.

300 Despite these variations, the overall spread of average temperature is $1.5 \mathrm{~K}$. Similar

301 results were obtained for other zones, in both the semi-detached and bungalow cases,

302 with similar overall spread of average temperatures being obtained.

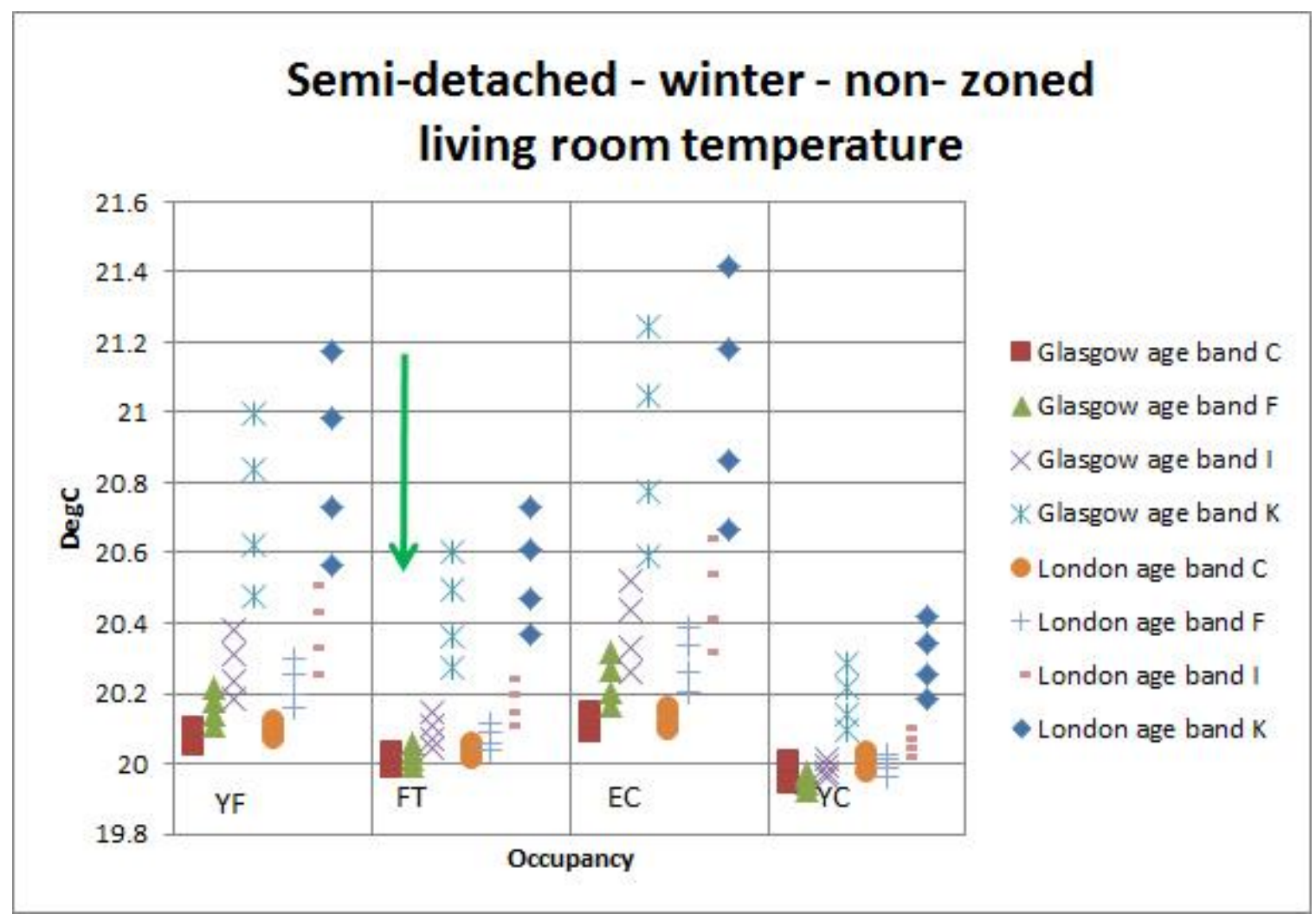

Figure 7 - effect of occupancy on change in living room temperature due to zoning (Semi-detached house, winter)

303 On comparing the results from the simulations with zoned controls, it is important that

304 average temperatures during the occupied periods in each zone are maintained close to 
305 set point, to ensure a fair comparison between the non-zoned and zoned results. Figure

3067 shows the effect of occupancy (YF, FT, EC and YC as described in the Model

307 Construction section) on the average living room temperature in the semi-detached

308 house during occupied hours for the zoned cases, minus that for the non-zoned cases.

309 For each occupancy type, the difference in average temperature is shown as a function

310 of climate (Glasgow or London), and house construction age band. For each case, a

311 range of four values is plotted corresponding to four door opening percentages $(0,10,50$

312 and $100 \%$ ). The arrow indicates the direction of increasing door opening area. The

313 smallest temperature differences correspond to the $100 \%$ door open cases, and the

314 largest differences to the $0 \%$ door open cases. This reflects the lower inter-zonal heat

315 transfers when the doors are closed. These differences, and the impact of door opening

316 percentage, are greater for the higher insulated and milder London climate cases, due to

317 the larger influence of inter-zonal heat transfer. However the range in each case is quite

318 small with a maximum reduction in average temperature less than $0.4 \mathrm{~K}$.

319 Similar results were obtained for other zones, in both the semi-detached and bungalow

320 cases, with a similar overall spread of temperature differences being obtained. This

321 raises confidence that the comparison of energy consumptions between the non-zoned

322 and zoned simulations is fair. 


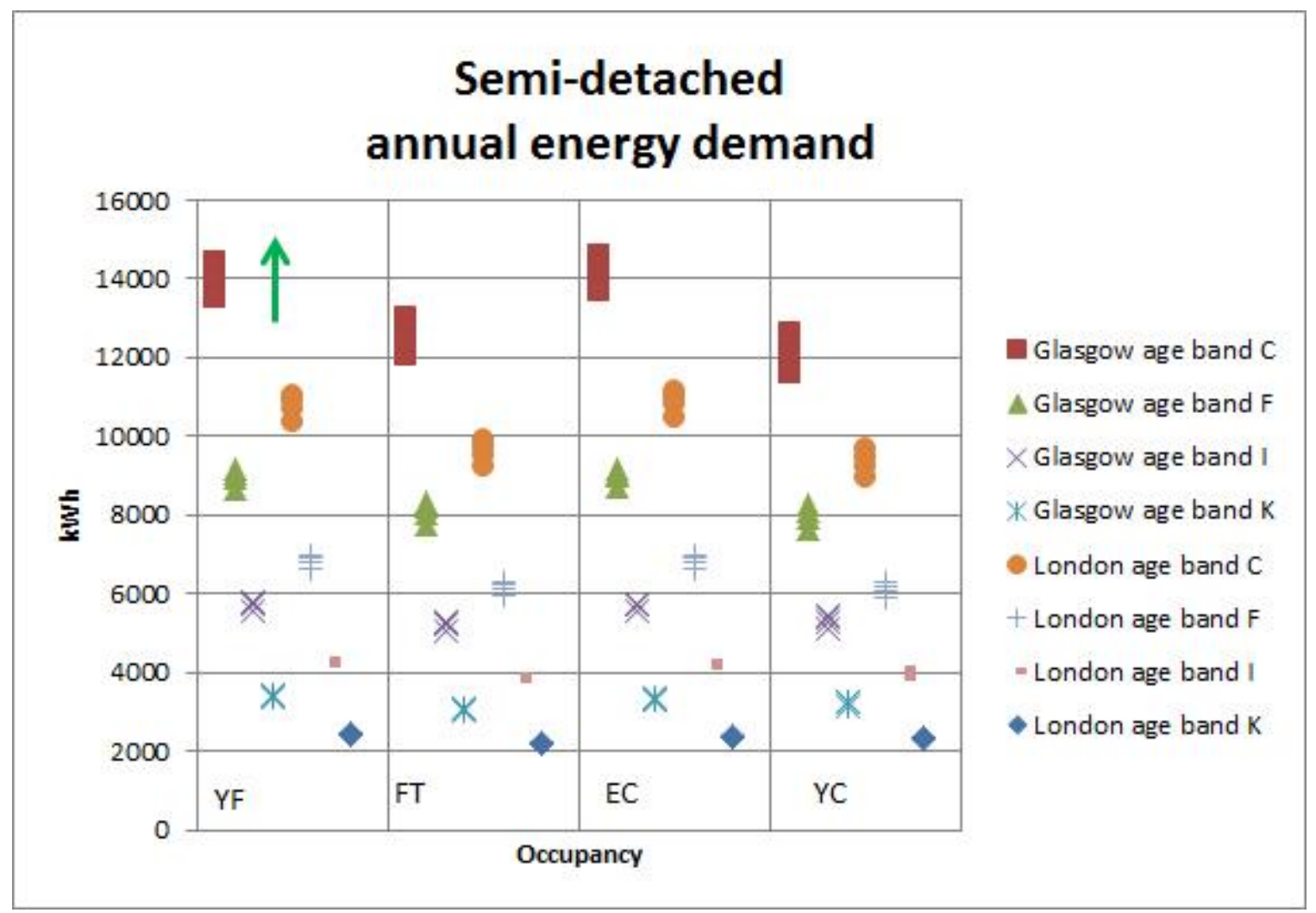

Figure 8 - Annual energy consumption for the semi-detached house, non-zoned.

323 The annual energy consumptions for the semi-detached house, non-zoned, are shown in

324 Figure 8. The pattern is as expected, with consumption reducing as insulation levels

325 improve, and less for the London climate than the Glasgow climate. The consumptions

326 for the FT and YC occupancy cases are slightly less than the YF and EC occupancy

327 cases due to longer periods of absence. The effect of door opening is quite small, as all

328 zones are heated together, minimising the effect of inter-zone heat transfer. The arrow

329 indicates the direction of increasing door opening area. Consumptions are slightly

330 higher at the $100 \%$ door openings due to greater inter-zonal heat transfer.

331 The annual energy saving for the semi-detached house due to zoning is shown in Figure

332 9. Savings as a percentage of the non-zoned energy consumption are hardly affected

333 by climate or age band. EC and YC occupancy cases exhibit larger savings than the YF

334 and FT cases. The differences are due to complex interacting factors, one of which is 
335 that both EC and YC 'couple' occupants have shorter evening bedroom heating periods

336 than the YF and FT 'family' occupants.

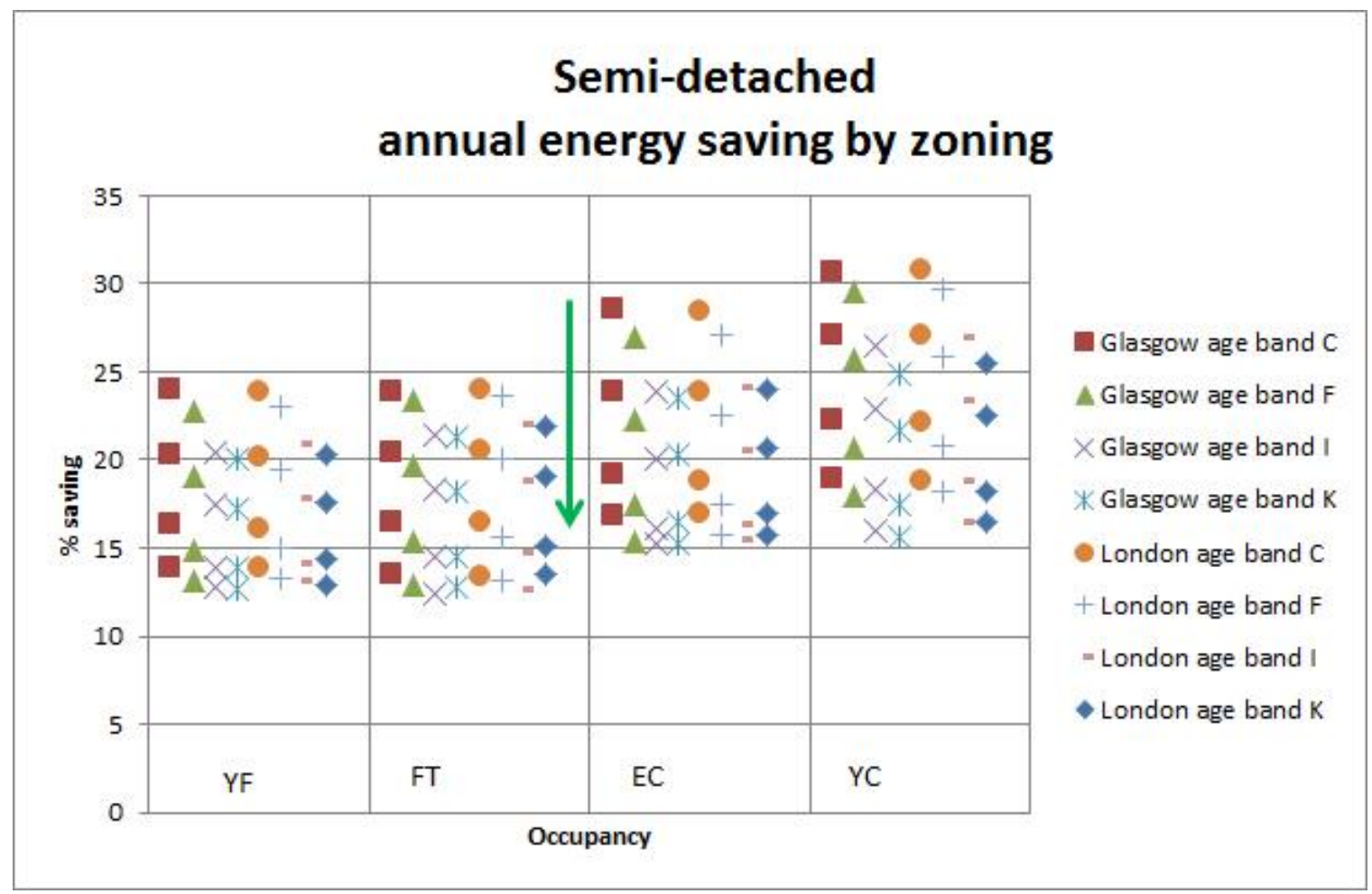

Figure 9 - energy saving in semi-detached house due to zoning

337 By far the biggest influence on saving is the door opening percentage (the arrow

338 indicates the direction of increasing door opening area) with $100 \%$ door opening almost

339 halving the saving obtainable if all doors are closed. This indicates that an effective

340 zoning strategy relies on isolating zones as far as possible to maximise the savings

341 benefit.

342 Although house age band has only a minor effect on savings potential as a percentage,

343 there is some tendency to reduced savings in better insulated houses. Of course, the

344 absolute savings will be lower, as the baseline non-zoned energy consumptions are

345 lower.

346 Overall, the savings obtainable across all simulations range from $12 \%$ to $31 \%$, with an

347 average around 19\%. 


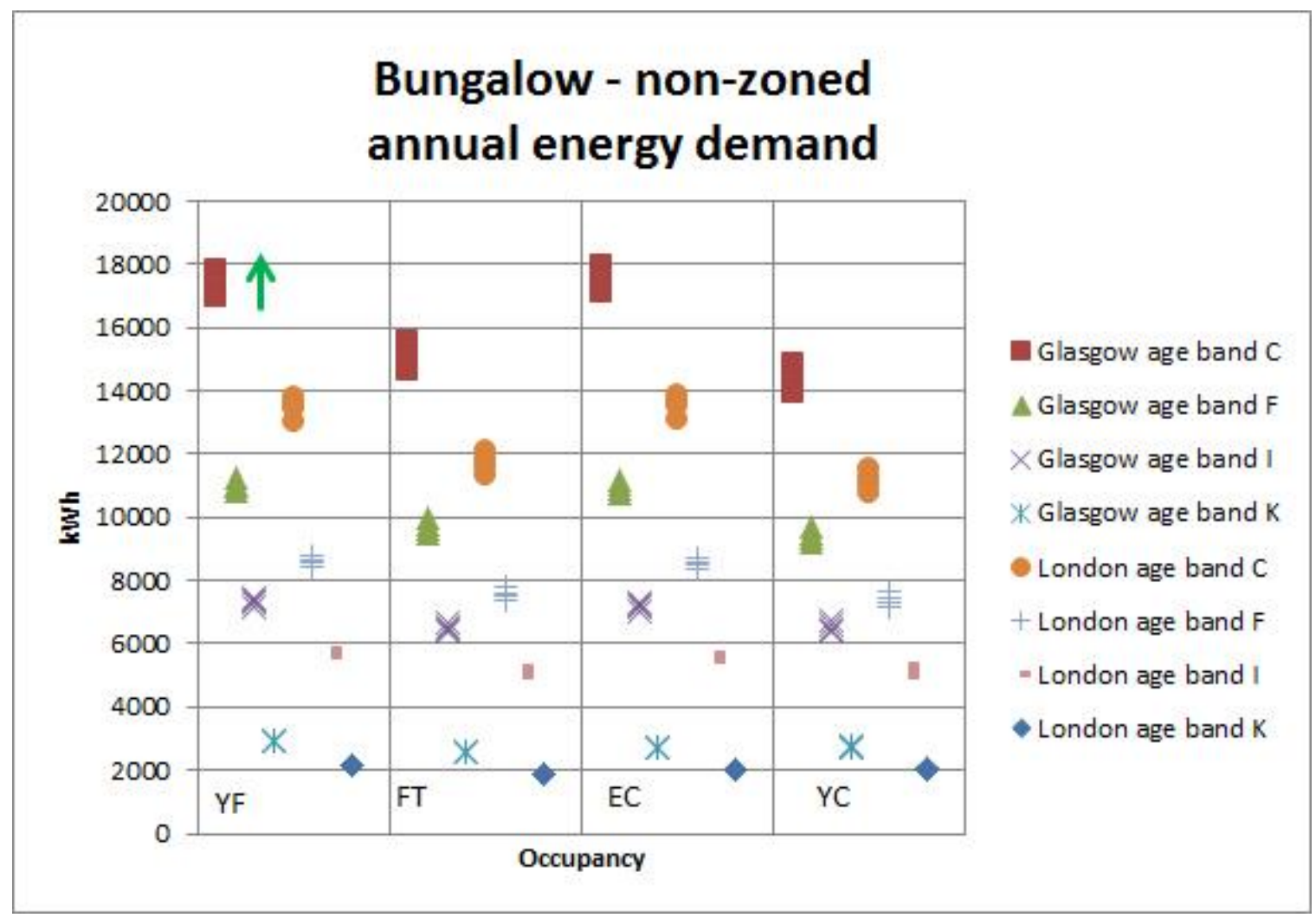

Figure 10 - Annual energy consumption for the bungalow, non-zoned

348 A similar pattern of energy consumptions for the bungalow as for the semi-detached

349 case can be seen in Figure 10. Overall consumptions are slightly higher than for the

350 semi-detached house, due to the lack of a party wall, and the less compact layout.

351 Again, the effect of door opening percentage is minor.

352 The annual energy saving for the bungalow due to zoning is shown in Figure 11. As in

353 the semi-detached case, savings as a percentage of the non-zoned energy consumption

354 are hardly affected by climate, and EC and YC occupancy cases exhibit larger savings

355 than the YF and FT cases. 


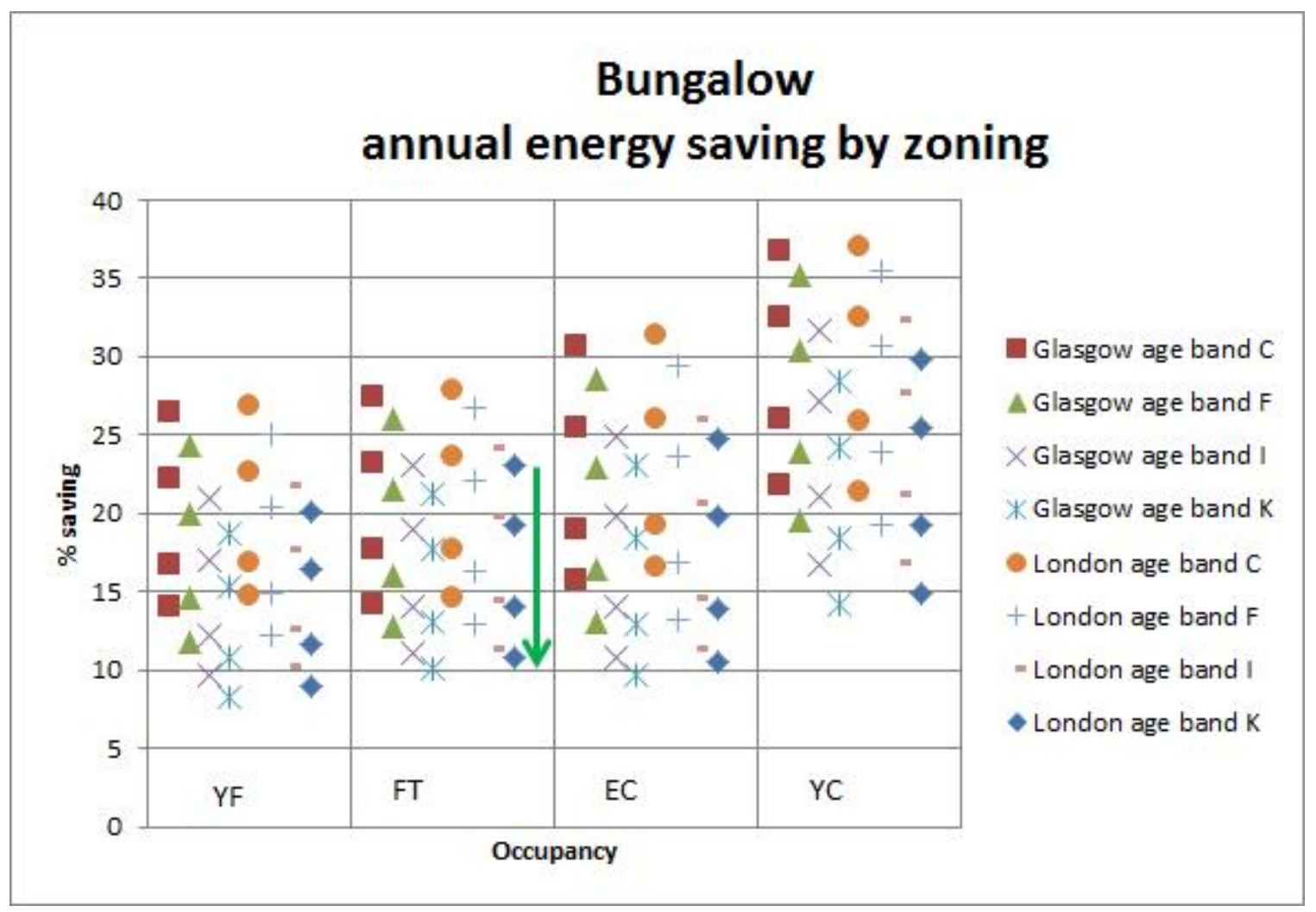

Figure 11 - energy saving in bungalow due to zoning

356 Again the biggest influence on saving is the door opening percentage (the arrow

357 indicates the direction of increasing door opening area). The effect of house age on

358 savings potential is somewhat more pronounced for the bungalow case, compared to the

359 semi-detached case. The bungalow house type has a greater proportion of exposed

360 fabric surface area, so the energy saving potential is greater in the older, poorly

361 insulated properties. The savings reduce to a level similar to the semi-detached house

362 type in the newer, better insulated properties.

363 Overall, the savings obtainable across all simulations range from $8 \%$ to $37 \%$, with an

364 average around $20 \%$. This is a wider spread of savings than was observed in the semi-

365 detached house.

366 The main difference in savings between the semi-detached and bungalow house types

367 is due to the reduced inter-zone heat transfer from living, dining and kitchen zones to the 
368 bedroom zones in the bungalow, compared to the semi-detached type where buoyancy

369 effects in the stairway, and upwards heat transfer through ceilings are present. However

370 the overall increase in savings is quite small, being greatest for the EC and $Y C$

371 occupancy types with doors closed.

372 Table 3 - Summary of energy savings \%

\begin{tabular}{|lr|rrrr|}
\hline & $\begin{array}{l}\text { Door } \\
\text { opening } \\
\text { \% }\end{array}$ & $\begin{array}{l}\text { Young } \\
\text { family }\end{array}$ & $\begin{array}{l}\text { Family } \\
\text { with } \\
\text { teens }\end{array}$ & $\begin{array}{l}\text { Elderly } \\
\text { couple }\end{array}$ & $\begin{array}{l}\text { Young } \\
\text { couple }\end{array}$ \\
\hline Semi- & 0 & 21.9 & 22.7 & 25.8 & 28.1 \\
detached & 10 & 18.6 & 19.4 & 21.8 & 24.5 \\
& 50 & 14.8 & 15.4 & 17.4 & 19.8 \\
Bungalow & 100 & 13.2 & 13.0 & 15.8 & 17.3 \\
& 10 & 23.0 & 25.0 & 27.3 & 33.3 \\
& 10.9 & 20.8 & 22.1 & 28.9 \\
& 50 & 13.8 & 15.4 & 15.9 & 22.5 \\
& 100 & 11.2 & 12.2 & 12.6 & 18.1 \\
\hline
\end{tabular}

373 Table 3 summarises the energy savings for each door opening and for each occupancy

374 type, these being the most significant influences. The figures are thus averages for the

375 two climate types and four age bands.

\section{Conclusions}

376 The simulation results show that significant energy savings are possible by adopting a

377 multi-zone control strategy, whereby temperature and time based control is applied

378 independently in each room of a typical house, compared with a non-zoned strategy,

379 whereby all rooms follow a single time/temperature profile. Confidence in these results

380 was provided by validating simulation results from a calibrated model against monitored

381 data, showing agreement in average energy saving to within $3 \%$.

382 The non-zoned strategy would be implemented using a seven day (or 5/2 day)

383 programmable timer, and single room thermostat, with thermostat or TRVs in all rooms.

384 This is typical installation practice for new central heating systems in the UK. The zoned 
385 strategy would require independently programmable radiator controls in each room.

386 Such control systems are now available from more than one manufacturer.

387 Savings potential is greatest where doors are kept closed for as much time as possible

388 (maybe through use of gravity or spring activated door closers), and for older, less well

389 insulated houses. If doors are kept closed, there is a risk that IAQ will be worse in the

390 occupied zones, so ensuring adequate ventilation is essential at a zonal level, and not

391 just a whole-house level. Savings are least where occupancy is relatively high, e.g. the

392 young family case. Climate was not a major factor in the percentage savings obtainable

393 in any case, for the two UK climates tested. Savings will be least in very low energy

394 demand housing, such as Passivhaus; in such cases it is unlikely the potential saving

395 will justify the investment.

396 Given the range of parameters studied here, a typical average saving of $20 \%$ seems to

397 be possible across a range of house types, ages, and occupancy patterns. These

398 savings are in-line with the limited previously reported studies on the benefits of zonal

399 control. This compares favourably with other demand reduction measures such as wall

400 insulation, or double glazing, and in many cases can be applied to an existing central

401 heating system. It is an attractive option where property architecture and conservation

402 considerations make other options difficult to apply. After having deployed the

403 applicable demand reduction measures, building integrated renewables and other low

404 carbon supply technologies may be considered. Future work should expand the range

405 of influencing factors, and in particular include door opening patterns as an element of

406 occupancy profiles. It should then be possible to evaluate how multi-zone control

407 techniques might fit into the portfolio of demand reduction measures for existing housing.

408 The favourable energy savings and low installation costs compared to alternative energy

409 saving technologies might encourage the development of intuitive user interfaces for the 
410 controls, to develop rigorous commissioning, and to educate users in the operation and

411 benefits.

412

413 This research did not receive any specific grant from funding agencies in the public,

414 commercial, or not-for-profit sectors.

\section{References}

415 Office of Gas and Electricity Markets (OFGEM), 2016, About the Domestic RHI.

416 https://www.ofgem.gov.uk/environmental-programmes/domestic-renewable-heat-

417 incentive/about-domestic-rhi

418 Office of Gas and Electricity Markets (OFGEM), 2016, Energy Company Obligation.

419 https://www.ofgem.gov.uk/environmental-programmes/energy-company-obligation-eco

420 HM Government, 2013. Domestic Building Services Design Guide,

421 http://www.planningportal.gov.uk/uploads/br/domestic_building_services_compliance_gu

422 ide.pdf

423 Consumer Focus 2012. Consumers and domestic heating controls: a literature review,

424 http://www.consumerfocus.org.uk/files/2012/01/Consumers-and-domestic-heating-

425 controls-a-literature-review.pdf

426 Clarke J A (2001) Energy Simulation in Building Design (2nd Edn), London: Butterworth-

427 Heinemann, ISBN 0750650826.

428 The Royal Academy of Engineering, 2010. Engineering a Low Carbon Built

429 Environment. www.raeng.org.uk

430 BRE, 2014.. The Government's Standard Assessment Procedure for Energy Rating of 431 Dwellings. 2012 Edition.BRE. Garston, UK.

432 Strachan P, Kokogiannakis G and Macdonald I, History and Development of Validation

433 with the ESP-r Simulation Program, Building and Environment, 43(4), April 2008, pp

434 601-609.

435 Beizaee A, Allinson D, Lomas K J, Foda E, Loveday D L, 2015. Measuring the potential 436 of zonal space heating controls to reduce energy use in UK homes: The case of un-

437 furbished 1930s dwellings. Energy \& Buildings Volume 92, Pages 29-44

438 Leow W L, Larson R C and Kirtley J L, 2013, Occupancy-moderated zonal space-

439 conditioning under a demand-driven electricity price, Energy and Buildings, 60, pp 453-

440463.

441 Liao Z, Swainson M and Dexter A, 2005, On the control of heating systems in the UK, 442 Building and Environment, 40, pp 343-51.

443 Meyers R J, Eric D. Williams E D and Matthews H S, 2010, Scoping the potential of 444 monitoring and control technologies to reduce energy use in homes, Energy and

445 Buildings, 42(5), pp 563-569. 
446 Peeters L, Van der Veken J, Hens H, Helsen L and D'haeseleer W, 2008, Control of 447 heating systems in residential buildings: current practice, Energy and Buildings, 40, pp 448 1446-1455.

449 Peffer T, Pritoni M, Meier A, Aragon C, and Perry D, 2011, How people use thermostats 450 in homes: A review, Building and Environment 46, pp 2529-2541

451 Rubens S and Knowles J, 2013, What people want from their heating controls: a 452 qualitative study. A report to the Department for Energy and Climate Change. new 453 experience. DECC, London, https://www.gov.uk/government/publications/what-people454 want-from-their-heating-controls-a-qualitative-study 


\section{Appendix A Occupancy profiles}

4564 profiles with and without zoning control; zoning control is employed using 3 zones (living, kitchen/dining and bedrooms). Profiles include $\{A=$ adult, $C=$ child $\}$ :

- $\quad \mathrm{YF}=$ Young family $(2 \mathrm{~A}+2 \mathrm{C}, 1 \mathrm{~A}$ works and $1 \mathrm{~A}$ looks after $2 \mathrm{C})$

- $\quad F T=$ Family with 2 teenagers $(2 A+2 A, 2 A$ work and $2 A$ teenagers study and party)

- $\quad \mathrm{YC}=$ Young couple (2A, both work and party)

- $\quad E C=$ Elderly couple (2A, both do not work)

\begin{tabular}{|c|c|c|c|c|c|c|c|c|}
\hline \multirow{3}{*}{ 心 } & \multirow[t]{3}{*}{ Parameter } & \multirow{3}{*}{$\begin{array}{l}\text { Day } \\
\text { type }\end{array}$} & \multicolumn{6}{|l|}{ Zones } \\
\hline & & & \multicolumn{2}{|l|}{ Living } & \multicolumn{2}{|c|}{ Kitchen/dining } & \multicolumn{2}{|c|}{ Bedrooms } \\
\hline & & & Timing & Occ'cy & Timing & Occ'cy & Timin & Occ'cy \\
\hline \multirow{10}{*}{ 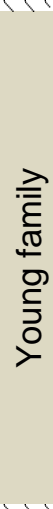 } & \multirow[t]{6}{*}{ Occupancy } & \multirow{3}{*}{ W'day } & $9-13$ & $1 A+2 C$ & $8-9$ & $2 A+2 C$ & $20-23$ & $2 \mathrm{C}$ \\
\hline & & & 16-18 & $1 A+2 C$ & $18-20$ & $2 A+2 C$ & $23-8$ & $2 A+2 C$ \\
\hline & & & $20-23$ & $2 A$ & & & & \\
\hline & & \multirow[t]{3}{*}{ W'end } & 9-13 & $2 A+2 C$ & \multirow{3}{*}{\multicolumn{4}{|c|}{ Same as weekdays }} \\
\hline & & & $16-18$ & $2 A+2 C$ & & & & \\
\hline & & & $20-23$ & $2 \mathrm{~A}$ & & & & \\
\hline & \multirow{2}{*}{\begin{tabular}{|l}
$\begin{array}{l}\text { Heating } \\
\text { (no zoning) }\end{array}$ \\
\end{tabular}} & W'day & \multicolumn{6}{|c|}{$6-13 \& 16-23$} \\
\hline & & W'end & \multicolumn{6}{|c|}{ Same as weekdays } \\
\hline & \multirow[t]{2}{*}{ Heating (zoning) } & W'day & \multicolumn{2}{|c|}{$8-13 \& 16-23$} & \multicolumn{2}{|c|}{$7-9 \& 18-20$} & \multicolumn{2}{|c|}{$6-8 \& 20-23$} \\
\hline & & W'end & \multicolumn{6}{|c|}{ Same as weekdays } \\
\hline \multirow{10}{*}{ 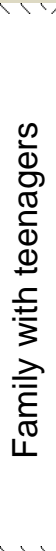 } & \multirow[t]{6}{*}{ Occupancy } & \multirow[t]{3}{*}{ W'day } & $16-18$ & $2 A$ & $8-9$ & $4 \mathrm{~A}$ & $7-8$ & $4 \mathrm{~A}$ \\
\hline & & & $20-23$ & $2 \mathrm{~A}$ & $18-20$ & $4 \mathrm{~A}$ & $20-23$ & $1 \mathrm{~A}$ \\
\hline & & & & & & & $23-7$ & $4 \mathrm{~A}$ \\
\hline & & \multirow[t]{3}{*}{ W'end } & $9-11$ & $4 \mathrm{~A}$ & \multirow{3}{*}{\multicolumn{2}{|c|}{$\begin{array}{l}\text { Same as } \\
\text { weekdays }\end{array}$}} & $7-8$ & $4 \mathrm{~A}$ \\
\hline & & & $16-18$ & $2 \mathrm{~A}$ & & & $23-7$ & $4 \mathrm{~A}$ \\
\hline & & & $20-23$ & $2 \mathrm{~A}$ & & & & \\
\hline & \multirow{2}{*}{$\begin{array}{l}\text { Heating } \\
\text { (no zoning) }\end{array}$} & W'day & \multicolumn{6}{|c|}{$6-9 \& 16-23$} \\
\hline & & W'end & $6-11 \&$ & $6-23$ & & & & \\
\hline & Heating (zoning) & W'day & $15-23$ & & $7-9 \&$ & -20 & 6-8 \& & \\
\hline & & W'end & 8-11\& & $6-23$ & $\begin{array}{l}\text { Same } \\
\text { weekd }\end{array}$ & & $6-8 \&$ & \\
\hline$\underline{0}$ & Occupancy & All & $9-13$ & $2 A$ & $8-9$ & $2 A$ & $7-8$ & $2 A$ \\
\hline 윽 & & & $15-18$ & $2 \mathrm{~A}$ & $18-20$ & $2 \mathrm{~A}$ & $23-7$ & $2 \mathrm{~A}$ \\
\hline 8 & & & $20-23$ & $2 \mathrm{~A}$ & & & & \\
\hline$\frac{\bar{亠}}{0}$ & Heating (no z'ing) & All & $6-13 \&$ & $5-23$ & & & & \\
\hline$\frac{0}{4}$ & Heating (zoning) & All & $8-13 \&$ & $5-23$ & $7-9 \& 1$ & -20 & 6-8 \& & \\
\hline & Occupancy & W'day & $20-23$ & $2 A$ & $8-9$ & $2 A$ & $7-8$ & $2 A$ \\
\hline & & & & & $18-20$ & $2 \mathrm{~A}$ & $23-7$ & $2 \mathrm{~A}$ \\
\hline$\frac{0}{0}$ & & W'end & $9-11$ & $2 A$ & Same & weekday & & \\
\hline 茨 & & & $20-23$ & $2 \mathrm{~A}$ & & & & \\
\hline 2 & Heating (no & W'day & $6-9 \& 1$ & -23 & & & & \\
\hline 气ิ & zoning) & W'end & $6-11 \&$ & $8-23$ & & & & \\
\hline & Heating (zoning) & W'day & $19-23$ & & $7-9 \& 1$ & -20 & $6-8 \&$ & \\
\hline & & W'end & $8-11,2$ & -23 & Same & weekday & & \\
\hline
\end{tabular}




\section{Appendix B Weather data summary}

464

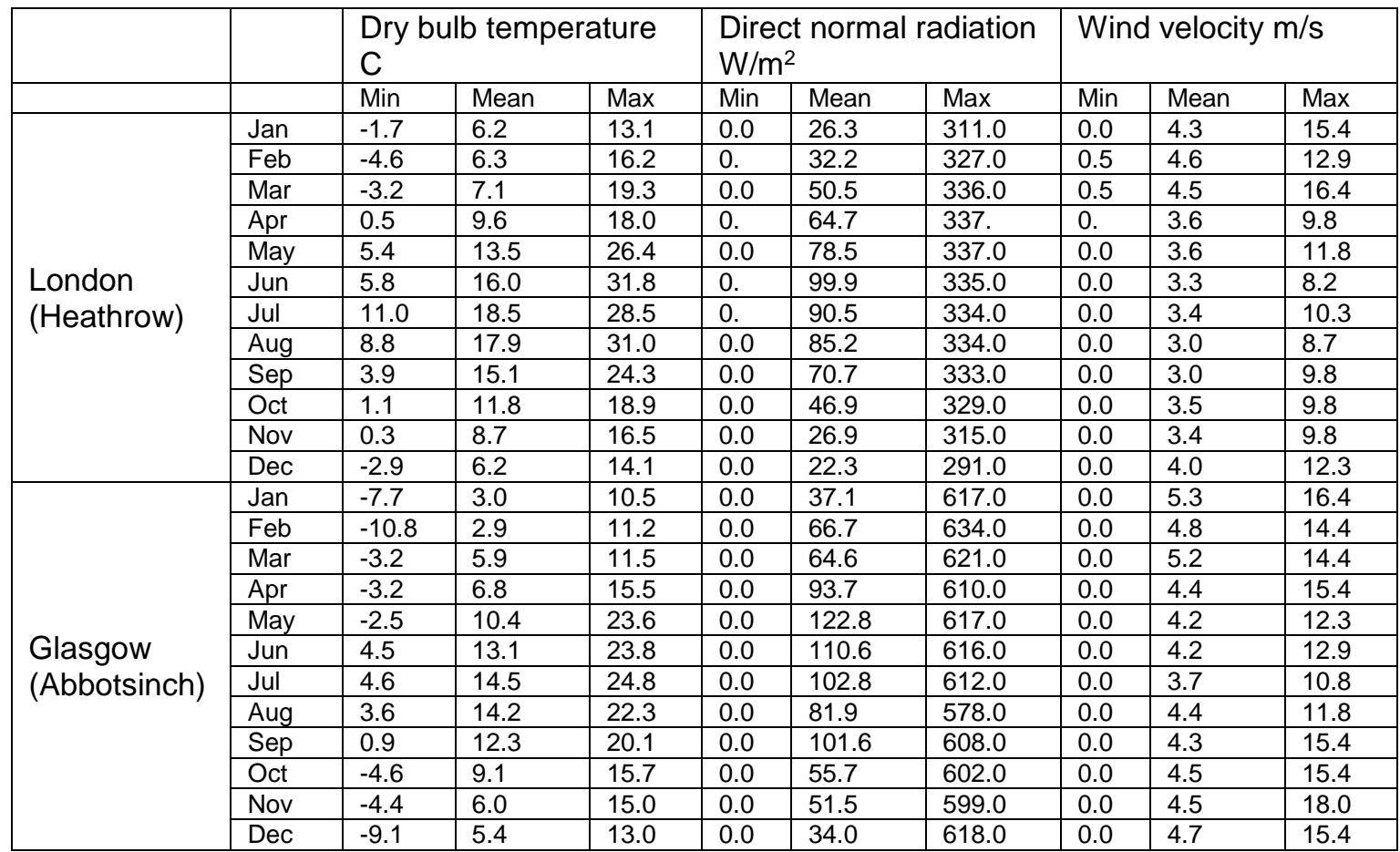

